\title{
pilF polymorphism-based real-time PCR to distinguish Vibrio vulnificus strains of human health relevance
}

\author{
Craig Baker-Austin ${ }^{\mathrm{a}, *}$, Elizabeth Lemm ${ }^{\mathrm{b}}$, Rachel Hartnell ${ }^{\mathrm{a}}$, James Lowther ${ }^{\mathrm{a}}$, Richard Onley ${ }^{\mathrm{b}}$, \\ Carmen Amaro ${ }^{\mathrm{d}}$, James D. Oliver ${ }^{\mathrm{c}}$, David Lees ${ }^{\mathrm{a}}$ \\ ${ }^{a}$ Centre for Environment Fisheries and Aquaculture Science, Barrack Road, Weymouth, Dorset DT4 8UB, UK \\ ${ }^{\mathrm{b}}$ University of Surrey, Guildford, Surrey, UK \\ ${ }^{\mathrm{c}}$ Department of Biology, University of North Carolina at Charlotte, Charlotte, North Carolina, USA \\ d Departamento de Microbiología, Facultad de Biología, Universidad de Valencia, Valencia, Spain
}

\section{A R T I C L E I N F O}

\section{Article history:}

Received 1 March 2011

Received in revised form

29 July 2011

Accepted 6 September 2011

Available online 16 September 2011

\section{Keywords:}

Pathogen

V. vulnificus

pilF

Real-time PCR

Detection

Oyster

\begin{abstract}
A B S T R A C T
The Gram-negative bacterium Vibrio vulnificus is a common inhabitant of estuarine environments. Globally, $V$. vulnificus is a significant foodborne pathogen capable of causing necrotizing wound infections and primary septicemia, and is a leading cause of seafood-related mortality. Unfortunately, molecular methods for the detection and enumeration of pathogenic $V$. vulnificus are hampered by the genetically diverse nature of this pathogen, the range of different biotypes capable of infecting humans and aquatic animals, and the fact that $V$. vulnificus contains pathogenic as well as non-pathogenic variants. Here we report an alternative approach utilizing the development of a real-time PCR assay for the detection of pathogenic $V$. vulnificus strains based on a polymorphism in pilF, a gene previously indicated to be associated with human pathogenicity. Compared to human serum reactivity, the real-time PCR assay successfully detected pathogenic strains in 46 out of 47 analysed $V$. vulnificus isolates (97.9\%). The method is also rapid, sensitive, and more importantly can be reliably utilised on biotype 2 and 3 strains, unlike other current methods for $V$. vulnificus virulence differentiation.
\end{abstract}

Crown Copyright @ 2011 Published by Elsevier Ltd. All rights reserved.

\section{Introduction}

The Gram-negative halophilic bacterium Vibrio vulnificus is a natural inhabitant of tropical as well as temperate estuarine environments. The species is present in high numbers in filtering organisms, such as oysters, especially in warmer months (Oliver, 2006). V. vulnificus is a potent human pathogen, and is responsible for more than $95 \%$ of all seafood-related deaths (Jones and Oliver, 2009). Isolated incidents of V. vulnificus infections occur globally, with cases frequently reported in the U.S.A., Europe and the Far East (Dalsgaard et al., 1996; Chuang et al., 1992; Hlady and Klontz, 1996; Baker-Austin et al., 2010a). Human infections typically occur after ingestion of raw or undercooked shellfish, particularly oysters, or through entry via a flesh wound (Oliver, 2005; Jones and Oliver, 2009). Significantly, V. vulnificus-associated primary septicemia carries the highest fatality rate of any foodborne pathogen (Rippey, 1994). A review of 459 U.S. cases reported by the Food and Drug Administration between 1992 and 2007 revealed that 51.6\% of the

\footnotetext{
* Corresponding author. Tel.: +4401305 206619; fax: +44 01305206601.

E-mail address: craig.baker-austin@cefas.co.uk (C. Baker-Austin).
}

patients infected with $V$. vulnificus died (Jones and Oliver, 2009). Most cases of infection ( $\sim 95 \%$ ) occur in males, who are immunocompromised or who have underlying diseases/syndromes which result in elevated serum iron levels, primarily liver cirrhosis secondary to alcohol abuse/alcoholism (Oliver and Kaper, 2001).

V. vulnificus is currently subdivided into three biotypes based on genetic, biochemical and serological features, as well as host range (Bisharat et al., 1999; Tison et al., 1982). Biotype 1 strains are human pathogens and are responsible for the vast majority of $V$. vulnificus infections reported worldwide. Biotype 2 contains strains which cause disease and infections in aquatic animals such as eels and occasionally in humans (Amaro and Biosca, 1996). A further biotype (biotype 3) was discovered in 1996 after an outbreak of $V$. vulnificus infections in an Israeli fish market, and was later found to be a hybrid of biotypes 1 and 2 (Bisharat et al., 2005). Not all strains of $V$. vulnificus appear to be able to cause disease in humans and aquatic animals, and there is a need for the development of accurate and rapid methods to distinguish virulent and avirulent isolates. V. vulnificus is phenotypically and serologically heterogeneous, has a wide host range encompassing different biotypes capable of infecting humans and aquatic animals, and this complexity has hampered efforts to provide a reliable assay to 
identify pathogenic and non-pathogenic variants. Several studies have utilised different molecular markers in biotype $1 \mathrm{~V}$. vulnificus as a proxy for potential human virulence, with varying degrees of success. Differences in the sequence of the small subunit 16S rRNA gene, as correlating with either clinical (pathogenic) and environmental (non-pathogenic) origin have been utilised previously (Aznar et al., 1994; Nilsson et al., 2003; Vickery et al., 2007). V. vulnificus biotype 1 strains have also been classified into two genotypes based on a virulence-correlated gene, $v c g$ (Rosche et al., 2005). This genotype has been correlated with human infection for $90 \%$ of isolates from human cases having the $v c g C$ sequence type and $87 \%$ of environmental strains having the $v c g E$ variant (Rosche et al., 2005). Both $16 \mathrm{~S}$ and $v c g$ polymorphism can be used as a predictive assay to distinguish pathogenic potential in biotype 1 V. vulnificus strains, but have failed to adequately identify biotype 2 and biotype 3 strains, which are also potentially pathogenic to humans (Sanjuan et al., 2009; Roig et al., 2010).

A recent report by Roig et al. (2010) demonstrated that a polymorphism in the pilus-type IV assembly protein of $V$. vulnificus can be utilised as a potential marker to distinguish pathogenic and nonpathogenic $V$. vulnificus strains, irrespective of biotype. The authors found that $V$. vulnificus strains appeared to be divided into two groups in terms of sequence variability in the pilF gene, which correlated strongly with potential pathogenicity (as ascertained by human serum sensitivity). PilF is a protein required for pilus-type IV assembly whose mutation in some bacterial pathogens results in attenuated virulence in mice models (Chakraborty et al., 2008).

The high mortality rates coupled to the rapidity of $V$. vulnificus infections underlie the need for additional assays to detect and enumerate these pathogens in a timely manner. The goal of the current study was the development and evaluation of a real-time PCR assay that would provide a rapid, sensitive and quantitative method for the detection of $V$. vulnificus strains encompassing the entire genetic diversity of human pathogenic isolates. A further objective of this work was the development of an assay that could be used successfully on extracted DNA, boiled cells, as well as directly in artificially spiked shellfish matrices.

\section{Materials and methods}

\subsection{Bacterial strains and growth conditions}

V. vulnificus strains, encompassing biotype 1, 2 and 3 isolates, were grown at $28^{\circ} \mathrm{C}$ for $24 \mathrm{~h}$ in tryptone soy broth or on solid agar media, supplemented with $5 \mathrm{~g} /$ liter $\mathrm{NaCl}$. Strains were cryogenically stored at $-80{ }^{\circ} \mathrm{C}$ prior to use, supplemented with $20 \%$ (vol/vol) glyerol. A total of 69 bacterial strains, including V. vulnificus $(n=47)$, other Vibrio species $(n=13)$, and distantly related reference strains $(n=9)$ were used to assess the specificity of the oligonucleotide probe and primer sets used.

\subsection{DNA isolation from individual strains}

Late-logarithmically grown bacterial suspensions were pelleted and DNA extracted using a Mini-prep protocol (Ausubel et al., 2007). The quality and quantity of DNA was subsequently ascertained spectrophotometrically using a NanoDrop ND1000 (NanoDrop Technologies, Wilmington, DE). Extracted DNA samples were coded to conceal their identity, and a separate laboratory scientist conducting the real-time PCR testing per strain was "blind" to the original identifier to minimize response measurement bias.

\subsection{Sequence analysis and TaqMan probe design}

The complete nucleotide sequences (open reading frame regions only) for all full length pilF nucleotide sequences, deposited by Roig et al. (2010), and encompassing GenBank accession numbers FJ756476-FJ756489 and FJ899603-FJ899608, were aligned using clustalW (Thompson et al., 1994). A region of the pilF genes (approximate position 481-601) was analysed using primer express software from DNASTAR (Madison, WI, USA). Initial sequence alignment comparisons identified a variable region, at approximate positions 534-571 in the pilF gene that demonstrated significant polymorphism for the design of an appropriate TaqMan probe (Fig. 1), targeting a sequence specific to human serumresistant strains. The probe and primers were subsequently assessed for species as well as strain specificity using a BLAST search against publically available databases (Table 1 ).

\subsection{Production of positive control material}

To produce appropriate positive control material for the pilF real-time PCR, the generation of cloned positive PCR was adopted. Briefly, for conventional PCR $50 \mu \mathrm{l}$ per reaction mixes consisted of $30.65 \mu \mathrm{l}$ molecular grade water, $10 \mu \mathrm{l} 5 \times$ Green GoTaq ${ }^{\circledR}$ Flexi Buffer (Promega), $0.62 \mu \mathrm{l}$ dNTP mixture ( $100 \mu \mathrm{M}$ each); $1.2 \mu \mathrm{l}$ of the pilF primers (100 $\mu \mathrm{M}$ each, Table 1$), 5 \mu \mathrm{l}$ of $\mathrm{MgCl}_{2}(25 \mathrm{mM}), 0.25 \mu \mathrm{l} \mathrm{Taq}$ flexi polymerase and $2.5 \mu \mathrm{l}$ of extracted DNA samples. The temperature profile for this assay consisted of 3 min denaturation at $94{ }^{\circ} \mathrm{C}$, followed by 30 cycles of $95^{\circ} \mathrm{C}$ for $45 \mathrm{~s}, 45 \mathrm{~s}$ at $55^{\circ} \mathrm{C}$ and

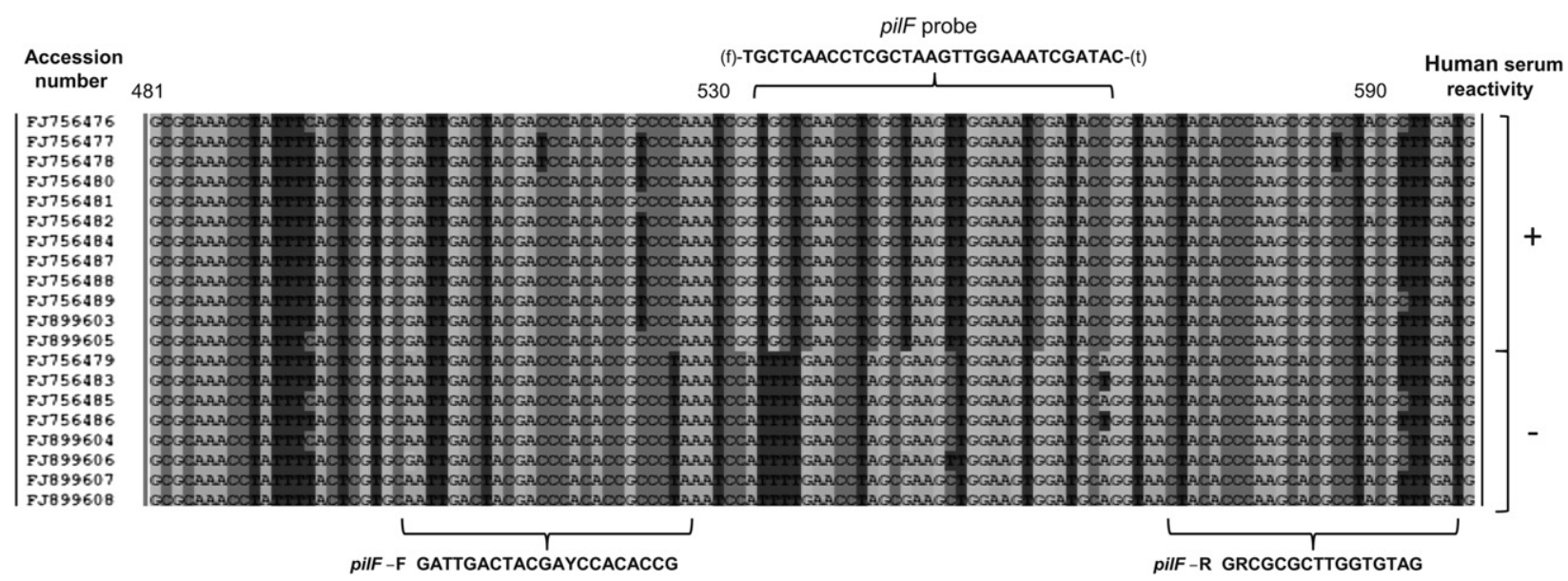

Fig. 1. Alignment of pilF gene sequences from a range of clinical and environmentally-derived V. vulnifius isolates, indicating primer binding regions used in this study. 
Table 1

Primers and probes used in this study.

\begin{tabular}{|c|c|c|}
\hline Name & Sequence (5'-3') & Reference \\
\hline Pil F-F & GATTGACTACGAYCCACACCG & This study \\
\hline Pil F-R & GRCGCGCTTGGGTGTAG & This study \\
\hline PilF Probe & (FAM)_TGCTCAACCTCGCTAAGTTGGAAATCGATAC-(TAMRA) & This study \\
\hline vvC-F & MMAAACTCATTGARCAGTAACGAAA & Baker-Austin et al. (2010b) \\
\hline vvC-R & AGCTGGATCTAAKCCCAATGC & Baker-Austin et al. (2010b) \\
\hline vcgC Probe & (TAMRA)_AATTAAAGCCGTCAAGCCACTTGACTGTAAAGAA-(FAM) & Baker-Austin et al. (2010b) \\
\hline
\end{tabular}

$72{ }^{\circ} \mathrm{C}$ for $45 \mathrm{~s}$ with a final extension step of $72{ }^{\circ} \mathrm{C}$ for 2 min. Following PCR, amplicons were visualised by ethidium bromide staining $(0.5 \mathrm{mg} / \mathrm{l})$ on $2.0 \%(\mathrm{wt} / \mathrm{vol})$ agarose gels. Positive PCR amplicons of predicted size were subsequently purified using a Qiagen PCR purification kit (Qiagen, Valencia, CA) following the manufacturer's recommendation and cloned into a TOPO ${ }^{\mathrm{TM}}$ ТA cloning kit (K4530-20, Invitrogen, Carlsbad, CA). Putative clones were tested by PCR and positive transconjugants were subsequently plasmid extracted using a Qiagen mini-prep kit (Qiagen, Valencia, CA). Plasmid DNA was subsequently serially diluted, and standard weight/volume concentrations were converted to pilF copies/microlitre concentrations by using the calculation: Copies per microliter $=$ grams per microliter $/ F W \times 6.0221415 \times 10^{23}$, where $\mathrm{FW}=$ Amplicon Length (in Base Pairs) $\times 660$. Known concentrations of pilF copies/microlitre were subsequently used for quantification purposes (Section 2.5).

\subsection{TaqMan PCR assay}

For real-time PCR experiments, the assay comprised of a total reaction of $25 \mu \mathrm{l}$, consisting of $12.5 \mu \mathrm{l}$ TaqMan Universal PCR Master Mix (Applied Biosystems), $0.45 \mu \mathrm{l}$ each of forward and reverse primer (as appropriate), $V$. vulnificus pilF and $v c g C$ primers (100 nM), $5.6 \mu \mathrm{l}$ nuclease-free water, and $1 \mu \mathrm{l}$ of probe $(500 \mathrm{nM}$, Table 1). Five microliters of template (either chromosomal DNA, plasmids, boiled cell lysate) was subsequently added, and each reaction was performed in triplicate. Amplification was performed using an Applied Biosystems SDS 7900 real-time PCR machine with the following cycling parameters: $1 \mathrm{cycle}$ at $95^{\circ} \mathrm{C}$ for $10 \mathrm{~min}$ followed by 50 cycles at $95^{\circ} \mathrm{C}$ for $15 \mathrm{~s}$ and $60^{\circ} \mathrm{C}$ for $90 \mathrm{~s}$. For each assay, samples generating a positive reaction result (sigmoid-shaped amplification curve rising above the threshold) in any replicate were considered positive. For each TaqMan sample replicate, a PCR unit quantity (genome copies of cloned pilF per reaction) was calculated using the slope of a standard curve of target DNA, with a $C_{p}$ value of 42.75 representing the theoretical limit of detection of the assay equalling 1 genome copy of target per PCR reaction. Standard curves for the determination of pilF DNA copy number (per PCR reaction) were constructed using the average of duplicate $C_{p}$ values encompassing a concentration range of four serially diluted cloned material samples (typically from -4 to -8 dilution of cloned material). Curves with $r^{2}$ values of $<0.99$ were not used for quantification purposes. Analysed TaqMan sample replicates that did not generate positive amplification curves were omitted from final analyses, and the average from the three replicates was calculated to give an overall quantity for that sample. To ascertain potential PCR inhibition, a commercially available amplification control was utilised (TaqMan ${ }^{\circledR}$ Exogenous internal positive control reagents, Applied Biosystems), with minor modifications. Briefly, each sample of extracted shellfish and extracted water $(5 \mu \mathrm{l})$ were analysed as above in triplicate, with the addition of $2.5 \mu \mathrm{l}$ of $10 \times$ EXO IPC mix, $0.51 \mu \mathrm{l}$ of $50 \times$ EXO IPC DNA, $12.5 \mu \mathrm{l}$ TaqMan Universal PCR Master Mix (Applied Biosystems), and $4.5 \mu$ of nuclease-free water. Inhibition in this context was defined by the absence of target amplification.

\subsection{Shellfish bioaccumulation and DNA extraction procedures}

For shellfish bioaccumulation experiments, four 50 litre capacity tanks ( 3 experimental and 1 control) were filled with $22 \mathrm{l}( \pm 0.5 \mathrm{l})$ sterile seawater and maintained at $15^{\circ} \mathrm{C}\left( \pm 1^{\circ} \mathrm{C}\right)$ with constant air sparging. Twenty-five un-depurated live Pacific oysters (Crassostrea gigas) were obtained from a local wholesaler (Weymouth, UK), evenly distributed into each tank and left for $24 \mathrm{~h}$ to acclimatise, prior to the addition of bacterial amendments. For bioaccumulation experiments, $V$. vulnificus strain E12 (a strain previously identified pilF positive by real-time PCR, Table 2) was grown up overnight in alkaline saline peptone water ASPW (Oxoid, Basingstoke, United Kingdom), and added to the test tank. The required quantities of bacterial amendments were assessed by analysing the cell cultures spectrophotometrically, and by adjusting the concentration of strain E12 in appropriate volumes of sterile ASPW prior to use. A spiking volume of strain E12 (optical density of 1) corresponding to approximately $10^{9}$ cells was added to the test tank and mixed. Ten C. gigas were removed after $6 \mathrm{~h}$ of exposure, and opened. For each sample, the digestive glands (stomach and digestive diverticula) were removed from each animal and weighed. The digestive glands were subsequently pooled together, and then finely chopped using a sterile razor blade. Homogenates were then prepared by treating the chopped digestive glands with $100 \mu \mathrm{g} / \mathrm{ml}$ Proteinase K solution (30 U/mg; Promega) as previously described (Jothikumar et al., 2005; Baker-Austin et al., 2010b). Homogenates were stored at $4{ }^{\circ} \mathrm{C}$ prior to testing. For each shellfish sample, $500 \mu \mathrm{l}$ of homogenate was processed using the NucliSens magnetic extraction kit (BioMerieux, Lyon, France) essentially following the manufacturer's instructions. Extracted samples (final volume $100 \mu \mathrm{l}$ ) were subsequently used directly in real-time PCR experiments.

\section{Results and discussion}

To date, no single molecular approach has been developed that can determine potential human pathogenicity in $V$. vulnificus strains with $100 \%$ accuracy and confidence, although recent studies have demonstrated the utility of combining several molecular virulence testing approaches simultaneously (Han and Ge, 2010). In this regard, we believe that pilF is a useful and reliable additional target for epidemiological and diagnostic tests alongside other reported assays for virulence testing in V. vulnificus, such as 16S rRNA (Aznar et al., 1994; Nilsson et al., 2003; Vickery et al., 2007), capsular polysaccharide genes (Han et al., 2009), and $v c g C$ and $v c g E$ analysis (Rosche et al., 2005; Baker-Austin et al., 2010b; Warner and Oliver, 2008).

Initial experiments using a cloned pilF fragment from strain E12, a previously identified pathogenic and $v c g C+V$. vulnificus isolate, showed excellent linear agreement $\left(r^{2}\right.$ 0.999) between the expected standard curve and detection of the pilF target (Fig. 2, inset B). Subsequent analysis of DNA diluted over 10 orders of magnitude was capable of reliably identifying this target using real-time PCR. Repeated analysis of highly diluted cloned material indicated that the observed limits of detection correspond to less than 5 copies of pilF per reaction, demonstrating optimum reaction kinetics of the 
Table 2

Bacterial strains analysed in this study.

\begin{tabular}{|c|c|c|c|c|}
\hline Strain & Isolation/origin & $v c g C$ RT-PCR & pilF RT-PCR & $\begin{array}{l}\text { Human } \\
\text { serum resistance }^{\mathrm{a}}\end{array}$ \\
\hline \multicolumn{5}{|c|}{ Vibrio vulnificus biotype 1 strains } \\
\hline ATCC 33816 & Human blood (USA) & + & + & + \\
\hline E12 & Oyster (USA) & + & + & + \\
\hline CECT 5168 & Human blood (USA) & + & + & + \\
\hline CECT 529 & Human blood (USA) & - & - & - \\
\hline V4 & Human blood (Australia) & + & + & + \\
\hline N87 & Human blood (Japan) & + & + & + \\
\hline KH03 & Human blood (Japan) & + & + & + \\
\hline YJ106 & Human blood (Taiwan) & + & + & + \\
\hline CECT 4867 & Diseased eel (Sweden) & - & - & - \\
\hline PD-1 & Eel tank water (Spain) & - & - & - \\
\hline L49 & Brackish water (Japan) & - & - & - \\
\hline Riu1 & Seawater (Spain) & - & + & - \\
\hline CECT 4608 & Eel farm water (Spain) & - & + & + \\
\hline CG100 & Oyster (Taiwan) & + & + & + \\
\hline CS9133 & Human blood (South Korea) & + & + & + \\
\hline CG106 & Oyster (Taiwan) & + & + & + \\
\hline СECT 4606 & Eel (Spain) & - & - & - \\
\hline \multicolumn{5}{|c|}{ Vibrio vulnificus biotype 2 strains } \\
\hline CECT 5198 & Diseased eel (Spain) & - & - & - \\
\hline A13 & Diseased eel (Spain) & - & - & - \\
\hline CECT 5769 & Diseased eel (Spain) & - & - & - \\
\hline A11 & Diseased eel (Spain) & - & - & - \\
\hline A14 & Diseased eel (Spain) & - & - & - \\
\hline $21 \mathrm{~A}$ & Diseased eel (Denmark) & - & $-{ }^{\mathrm{b}}$ & - \\
\hline 22 & Diseased eel (Denmark) & - & - & - \\
\hline 27 & Diseased eel (Denmark) & - & - & - \\
\hline CECT 4862 & Diseased eel (Japan) & - & + & + \\
\hline CECT 4604 & Diseased eel (Spain) & + & + & + \\
\hline СЕCT 4999 & Diseased eel (Spain) & - & + & + \\
\hline CECT 5763 & Eel tank water (Spain) & - & + & + \\
\hline CIP8190 & Human blood (France) & - & + & + \\
\hline CECT 4866 & Human blood (Australia) & - & + & + \\
\hline CECT 5762 & Healthy eel (Spain) & - & + & + \\
\hline Riu-2 & Seawater (Spain) & - & + & + \\
\hline CECT 4868 & Diseased eel (Norway) & - & + & + \\
\hline $90-2-11$ & Diseased eel (Denmark) & - & + & + \\
\hline $94-8-112$ & Human wound (Denmark) & - & + & + \\
\hline $94-9-123$ & Seawater (Denmark) & - & + & + \\
\hline CECT 4865 & Diseased shrimp (Taiwan) & - & + & + \\
\hline UE516 & Diseased eel (Taiwan) & - & + & + \\
\hline СЕСТ 897 & Diseased eel (Japan) & - & + & + \\
\hline $95-8-162$ & Diseased eel (Denmark) & - & + & + \\
\hline $95-8-6$ & Diseased eel (Denmark) & - & $-{ }^{\mathrm{b}}$ & - \\
\hline \multicolumn{5}{|c|}{ Vibrio vulnificus biotype 3 strains (Serovar O) } \\
\hline 11028 & Human disease (Israel) & - & + & + \\
\hline 162 & Human disease (Israel) & - & + & + \\
\hline 12 & Human disease (Israel) & - & + & + \\
\hline 32 & Human disease (Israel) & - & + & + \\
\hline 97 & Human disease (Israel) & - & + & + \\
\hline \multicolumn{5}{|l|}{ Other Vibrio spp. } \\
\hline V. fluvialis VF10 & Type strain NCTC 11327 & - & - & NA \\
\hline V. cholerae VC9 & Type strain NCTC 80442 & - & - & NA \\
\hline V. alginolyticus & $05 / 073$ & - & - & NA \\
\hline V. cholerae & V05/086 & - & - & NA \\
\hline V. fluvialis & Type strain NCTC 11327 & - & - & NA \\
\hline V. parahaemolyticus & V05/070 & - & - & NA \\
\hline V. parahaemolyticus & V05/086 & - & - & NA \\
\hline V.parahaemolyticus & Type strain NCTC 10885 & - & - & NA \\
\hline V. parahaemolyticus & V05/062 & - & - & NA \\
\hline V. furnissi & V06/003 & - & - & NA \\
\hline V. cincinnatiensis & V06/001 & - & - & NA \\
\hline V. metschinovii & V06/004 & - & - & NA \\
\hline V. mimicus & V06/300 & - & - & NA \\
\hline \multicolumn{5}{|l|}{ Other bacteria } \\
\hline S. paucimobilis SP21 & Type strain NCTC 11030 & - & - & NA \\
\hline S. nottingham & Type strain NCTC 7832 & - & - & NA \\
\hline R. planticola & Type strain NCTC 9528 & - & - & NA \\
\hline P. aeruginosa PA20 & Type strain NCTC 10332 & - & - & NA \\
\hline P. mirabilis PM22 & Type strain NCTC 10975 & - & - & NA \\
\hline E.coli $\mathrm{E} 012$ & Type strain NCTC 12241 & - & - & NA \\
\hline
\end{tabular}


Table 2 (continued)

\begin{tabular}{|c|c|c|c|c|}
\hline Strain & Isolation/origin & $v c g C$ RT-PCR & pilF RT-PCR & $\begin{array}{l}\text { Human } \\
\text { serum resistance }^{a}\end{array}$ \\
\hline E.coli ECL13 & Type strain NCTC 13216 & - & - & NA \\
\hline K. aerogenes KA23 & Type strain NCTC 9528 & - & - & NA \\
\hline E. faecalis EF9 & Type strain NCTC 775 & - & - & NA \\
\hline
\end{tabular}

real-time PCR assay. The species specificity of the real-time PCR assay was evaluated by testing pathogenic and non-pathogenic $V$. vulnificus strains (deemed pathogenic to humans based on previous human serum reactivity analysis), as well as a range of closely and distantly related bacteria. To compare pilF with established pathogenicity analysis we analysed strains using $v \operatorname{cgC}$ realtime PCR, an assay previously shown to successfully identify pathogenic biotype $1 \mathrm{~V}$. vulnificus isolates (Baker-Austin et al., 2010b). In agreement with previous work (Roig et al., 2010), the results here demonstrated that the pilf was capable of correctly identifying the vast majority of human serum-resistant strains, irrespective of biotype (Table 2). Of the 17 biotype $1 \mathrm{~V}$. vulnificus strains analysed for pilF and $v c g C, 16$ strains were correctly identified by both assays (94.1\%). Of the 25 biotype 2 strains analysed, only 9 strains were correctly identified using $v c g C$ real-time PCR, compared to 25 using pilF (36\% and $100 \%$ identifications, respectively). All five biotype three strains were correctly identified using pilF (100\%), whilst no positive results were detected by $v c g C(0 \%)$, Table 2. No amplification of closely related vibrio or non-vibrio strains were observed, indicating the specificity of the pilf realtime PCR assay (Table 2). The pilF assay thus contrasts with other targets used to identify pathogenic strains of $V$. vulnificus, such as 16S rRNA (Aznar et al., 1994; Nilsson et al., 2003; Vickery et al., 2007) and $v c g C$ polymorphisms (Rosche et al., 2005; Warner and Oliver, 2008; Baker-Austin et al., 2010b), which have shown limited usefulness in detecting biotype 2 and biotype $3 \mathrm{~V}$. vulnificus strains potentially dangerous to human health (Roig et al., 2010; Sanjuan et al., 2009). Both biotype 2 (serovar E and serovar I) and biotype $3 \mathrm{~V}$. vulnificus strains represent important human pathogens (Amaro and Biosca, 1996; Bisharat et al., 1999), and the ability to identify potentially virulent strains rapidly is of paramount importance. We found that a small number of non-pathogenic $V$. vulnificus strains (i.e. isolates possessing no serum resistance) did demonstrate weak amplification when analysed with the pilF real-time PCR assay (Table 2). However, these strains did not show true sigmoidal amplification curves, which were evident in all analysed human serum resistant $V$. vulnificus strains (data not shown). The non-specific amplifications are probably caused by the relatively close sequence homology of the two major polymorphisms in the pilF gene, whereby some co-amplification of nonpathogenic pilF DNA from non-pathogenic strains is difficult to eliminate. We found that reducing the number of thermal cycles, increasing the cycle threshold and iterative analysis of all amplifications during the real-time PCR assay successfully eliminated these false-positive results. Irrespective, several strains producing discordant results are currently subject to in-depth characterization including additional human serum analysis and genomic sequencing to glean additional insights into the pathogenic potential of these isolates.

Real-time PCR demonstrated a strong dynamic range of detection, with samples reliably detected from cloned plasmid template diluted to over 9 orders of magnitude in serial dilution experiments (Fig. 2), corresponding to single number copies of pilF per PCR reaction. Real-time PCR assays were performed on DNA extracted from bioaccumulated shellfish samples (Fig. 3). We were able to identify pilF directly from shellfish matrices (Pacific oyster, average $C_{t}$ value 28.99, Fig. 3), whereas no signal was evident from negative control samples (no vibrio amendment), or from extracted water. No matrix (shellfish tissue) inhibition was observed during these experiments. The results from artificially bioaccumulated samples (Fig. 3) correspond to detection of approximately 7600 genome copies of pilF per reaction based on cloned pilF target DNA (Section

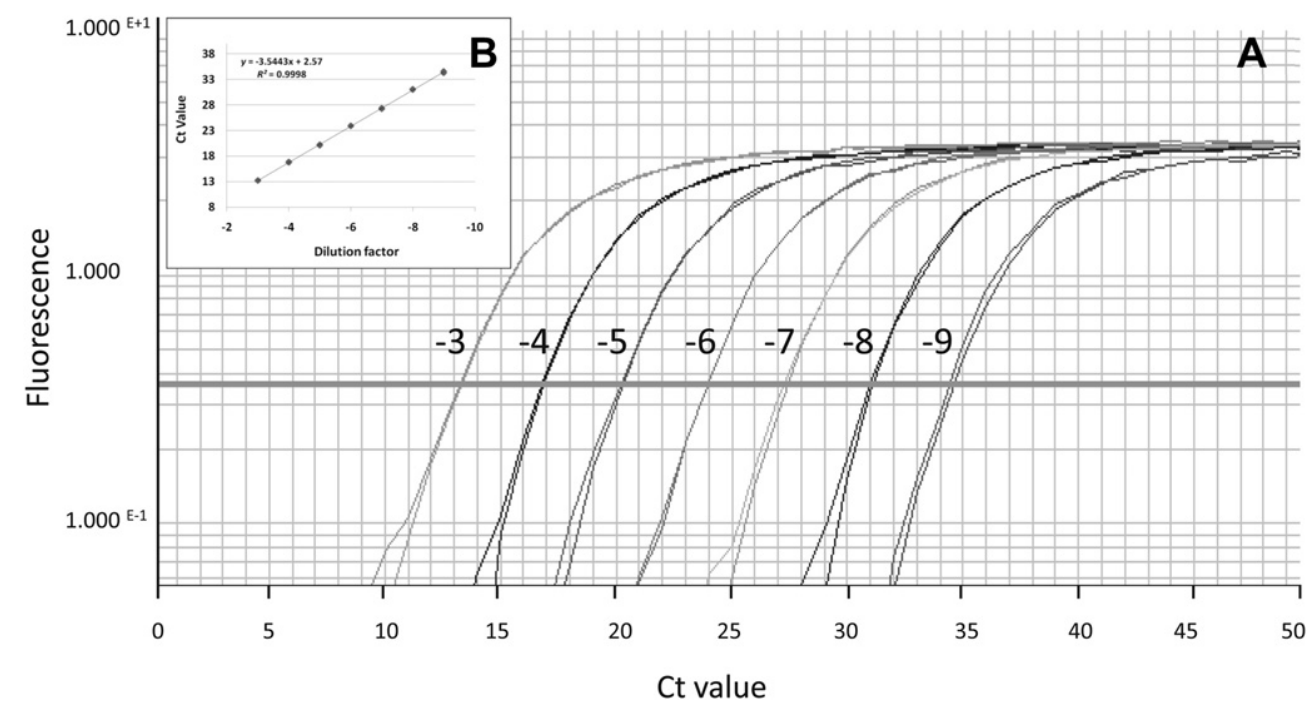

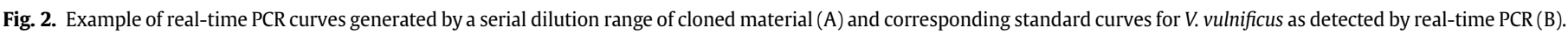




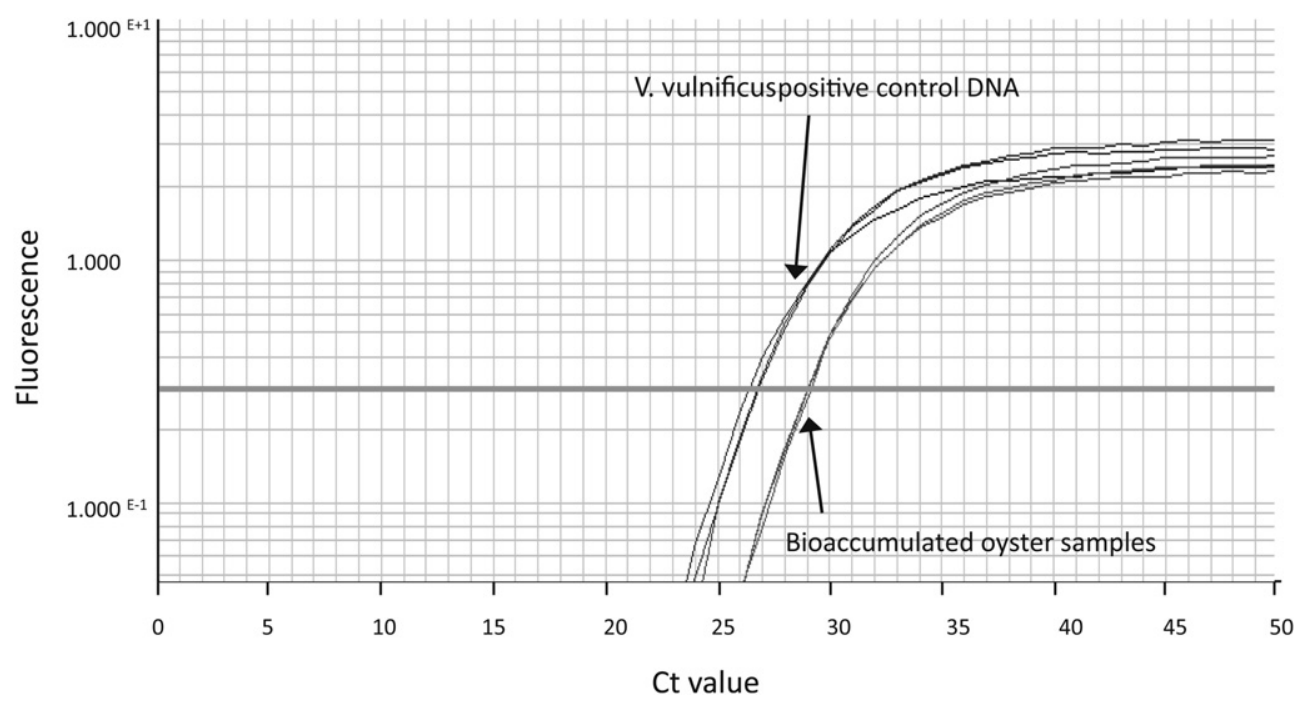

Fig. 3. Detection of pilF in artificially amended shellfish matrices.

2.5), highlighting the sensitivity of this approach for detection purposes in shellfish matrices. These results mirror prior findings (Baker-Austin et al., 2010b) which demonstrated that the nucleic acid extraction procedure detailed here can be used to directly extract bacterial nucleic acids from shellfish matrices, without the need for prior enrichment of samples. Given the promising sensitivity of this assay, the ability to identify pathogenic $V$. vulnificus from naturally contaminated rather than artificially spiked samples is an area that will be further investigated in future work.

In conclusion, this real-time PCR assay represents a rapid means of distinguishing $V$. vulnificus strains potentially harmful to human health, irrespective of biotype. The assay was applied to single cultures, extracted DNA and to artificially bioaccumulated shellfish samples, and is an especially useful target to detect potentially pathogenic biotype 2 and 3 strains of human health relevance. This tool will enable early detection capability in a range of different applications, such as food processing, regulatory and clinical settings.

\section{Acknowledgments}

We would like to that F. Roig for technical assistance. The European Community Reference laboratory is funded by D.G. Sanco of the European Commission, with matching funding by the Department of Environment, Food and Rural Affairs, and the Food Standards Agency of the United Kingdom. This work has been partially financed by grants AGL2008-03977/ACU and Programa Consolider-Ingenio CSD2009-00006 from MICINN (Spain).

\section{References}

Amaro, C., Biosca, E.G., 1996. Vibrio vulnificus biotype 2, pathogenic for eels, is also an opportunistic pathogen for humans. Applied and Environmental Microbiology 62, 1454-1457.

Ausubel, F.M., Brent, R., Kingston, R.E., Moore, D.D., Seidman, J.G., Smith, J.A., Struhl, K., 2007. Current Protocols in Molecular Biology. Wiley Interscience, New York, NY.

Aznar, R., Ludwig, W., Amann, R.I., Schleifer, K.H., 1994. Sequence determination of rRNA genes of pathogenic Vibrio species and whole-cell identification of Vibrio vulnificus with rRNA-targeted oligonucleotide probes. International Journal of Systematic Bacteriology 44, 330-337.

Baker-Austin, C., Stockley, L., Rangdale, R., Martinez-Urtaza, J., 2010a. Environmental occurrence and clinical impact of Vibrio vulnificus and Vibrio parahaemolyticus: a European perspective. Environmental Microbiology Reports 2, 7-11.
Baker-Austin, C., Gore, A., Oliver, J., Rangdale, R., Lees, D.N., 2010b. Rapid in situ detection of virulent Vibrio vulnificus strains in shellfish matrices using realtime PCR. Environmental Microbiology Reports 2, 76-80.

Bisharat, N., Agmon, V., Finkelstein, R., Raz, R., Ben-Dror, G., Lerner, L., Soboh, S. Colodner, R., Cameron, D.N., Wykstra, D.L., Swerdlow, D.L., Farmer, J.J., et al, 1999. Clinical, epidemiological, and microbiological features of Vibrio vulnificus biogroup 3 causing outbreaks of wound infection and bacteremia in Israel. Lancet 354, 1421-1424.

Bisharat, N., Cohen, D.I., Harding, R.M., Falush, D., Crook, D.W., Peto, T. Maiden, M.C., 2005. Hybrid Vibrio vulnificus. Emerging Infectious Diseases 11 30-35.

Chakraborty, S., Monfett, M., Maier, T.M., Benach, J.L., Frank, D.W., Thanassi, D.G. 2008. Type IV pili in Francisella tularensis: roles of pilF and pilT in fiber assembly, host cell adherence, and virulence. Infection and Immunity 76 , 2852-2861.

Chuang, Y.C., Yuan, C.Y., Liu, C.Y., Lan, C.K., Huang, A.H., 1992. Vibrio vulnificus infection in Taiwan: report of 28 cases and review of clinical manifestations and treatment. Clinical Infectious Diseases 15, 271-276.

Dalsgaard, A., Frimodt-Moller, N., Bruun, B., Hoi, L., Larsen, J.L., 1996. Clinical manifestations and molecular epidemiology of Vibrio vulnificus infections in Denmark. European Journal of Clinical Microbiology \& Infectious Disease 15, 227-232.

Han, F., Pu, S., Hou, A., Ge, B., 2009. Characterization of clinical and environmenta types of Vibrio vulnificus isolates from Louisiana oysters. Foodborne Pathogens \& Disease 6, 1251-1258.

Han, F., Ge, B., 2010. Multiplex PCR assays for simultaneous detection and characterization of Vibrio vulnificus strains. Letters in Applied Microbiology 51 234-240.

Hlady, W.G., Klontz, K.C., 1996. The epidemiology of Vibrio infections in Florida, 1981-1993. Journal of Infection Disease 173, 1176-1183.

Jones, M.K., Oliver, J.D., 2009. Vibrio vulnificus: disease and pathogenesis. Infection \& Immunity 77, 1723-1733.

Jothikumar, N., Lowther, J.A., Henshilwood, K., Lees, D.N., Hill, V.R., Vinjé, J., 2005 Rapid and sensitive detection of noroviruses by using TaqMan-based onestep reverse transcription-PCR assays and application to naturally contaminated shellfish samples. Applied \& Environmental Microbiology 71, 1870-1875.

Nilsson, W.B., Paranjpye, R.N., DePaola, A., Strom, M.S., 2003. Sequence polymorphism of the 16S rRNA gene of Vibrio vulnificus is a possible indicator of strain virulence. Journal of Clinical Microbiology 41, 442-446.

Oliver, J.D., 2005. Wound infections caused by Vibrio vulnificus and other marine bacteria. Epidemiology \& Infection 133, 383-391.

Oliver, J.D., 2006. Vibrio vulnificus. In: Thompson, F.L., Austin, B., Swing, J. (Eds.), Biology of Vibrios. Amer. Soc. Microbiol. Press, Washington, DC, pp. 349-366.

Oliver, J.D., Kaper, J., 2001. Vibrio species. In: Doyle, M.P., et al. (Eds.), Food Microbiology: Fundamentals and Frontiers, pp. 263-300.

Rippey, S.R., 1994. Infectious diseases associated with molluscan shellfish consumption. Clinical Microbiology Reviews 7, 419-425.

Roig, F.J., Sanjuán, E., Llorens, A., Amaro, C., 2010. PilF polymorphism-based PCR to distinguish Vibrio vulnificus strains potentially dangerous to public health. Applied \& Environmental Microbiology 76, 1328-1333.

Rosche, T.M., Yano, Y., Oliver, J.D., 2005. A rapid and simple PCR analysis indicates there are two subgroups of Vibrio vulnificus which correlate with clinical or environmental isolation. Microbiology \& Immunology 49, 381-389. 
Sanjuan, E., Fouz, B., Oliver, J.D., Amaro, C., 2009. Evaluation of genotypic and phenotypic methods to distinguish clinical from environmental Vibrio vulnificus strains. Applied \& Environmental Microbiology 75, 1604-1613.

Tison, D.L., Nishibuchi, M., Greenwood, J.D., Seidler, R.J., 1982. Vibrio vulnificus biogroup 2: new biogroup pathogenic for eels. Applied \& Environmental Microbiology 44, 640-646.

Thompson, J.D., Higgins, D.G., Gibson, T.J., 1994. CLUSTAL W: improving the sensitivity of progressive multiple sequence alignment through sequence weighting position-specific gap penalties and weight matrix choice. Nucleic Acids Research 22, 4673-4680.

Vickery, M.C., Nilsson, W.B., Strom, M.S., Nordstrom, J.L., DePaola, A., 2007. A realtime PCR assay for the rapid determination of 16S rRNA genotype in Vibrio vulnificus. Journal of Microbiological Methods 68, 376-384.

Warner, E.B., Oliver, J.D., 2008. Multiplex PCR assay for detection and simultaneous differentiation of genotypes of Vibrio vulnificus biotype 1. Foodborne Pathogens \& Disease 5, 691-693. 